\title{
Lightweight Nonmetallic Thermal Protection Materials Technology
}

\author{
Peter G. Valentine ${ }^{1 \mathrm{a}}$, Timothy W. Lawrence ${ }^{1 \mathrm{a}}$, Michael K. Gubert $^{\text {1b }}$, \\ Frank S. Milos ${ }^{2}$, Stanley R. Levine ${ }^{3}$, Craig W. Ohlhorst ${ }^{4}$, and John R. Koenig ${ }^{5}$ \\ ${ }^{l a}$ Engineering Directorate and ${ }^{l b}$ Sverdrup Technology, Inc., NASA Marshall Space Flight Center, Huntsville, AL \\ 35812, USA \\ ${ }^{2}$ Space Technology Division, NASA Ames Research Center, Moffett Field, CA 94035, USA \\ ${ }^{3}$ Research and Technology Directorate, NASA Glenn Research Center, Cleveland, OH 44135, USA \\ ${ }^{4}$ Structures and Material Competency, NASA Langley Research Center, Hampton, VA 23681, USA \\ ${ }^{5}$ Materials Research Department, Southern Research Institute, Birmingham, AL 35211, USA \\ ${ }^{1 a} 256-544-2837,256-544-5877$, Peter.G.Valentine@nasa.gov
}

\begin{abstract}
To fulfill President George W. Bush's "Vision for Space Exploration" (2004) — successful human and robotic missions to and from other solar system bodies in order to explore their atmospheres and surfaces - the National Aeronautics and Space Administration (NASA) must reduce the trip time, cost, and vehicle weight so that the payload and scientific experiments' capabilities can be maximized. The new project described in this paper will generate thermal protection system (TPS) products that will enable greater fidelity in mission/vehicle design trade studies, support risk reduction for material selections, assist in the optimization of vehicle weights, and provide materials and processes templates for use in the development of human-rated TPS qualification and certification plans.
\end{abstract}

\section{INTRODUCTION}

For National Aeronautics and Space Administration (NASA) human-rated programs, the greater part of thermal protection system (TPS) heat shield development occurred in the early years of the Apollo Program (Chauvin, L.T., Erb, R.B., Greenshields, D.H., Pavlosky, J.E., and Statham, C.L., 1970; Pavlosky, J.E. and St.leger, L.G., 1974; Schaefer, J.W., Flood, D.T., Reese, J.J., J.., and Clark, K.J., 1967a; Schaefer, J.W., Flood, D.T., Reese, J.J., Jr., and Clark, K.J., 1967b) (for ablative materials) and during development of the Space Shuttle (Greenshields, D.H., 1977; 1974a; 1974b; 1980) (for reusable nonablative materials). For unmanned, relatively small payload missions to the planets, the Viking program's super lightweight ablative (SLA-561-V, developed by Martin Marietta) has been the heat shield material of choice.

Extensive resources were invested in the testing and characterization of these TPS materials for the Apollo, Shuttle, and Viking programs. Materials and processes building-block approaches were used to develop these materials. Extensive material properties testing (physical, thermal, and mechanical) was conducted over a range of temperatures and pressures. Materials were subjected to combined loads environmental testing, testing in vacuum, and testing at both elevated and cryogenic temperatures. Environmental effects testing occurred both in the predicted relevant space environments (proton, electron, ultraviolet, atomic oxygen, etc.) and in simulated aeroentry environments (arc jets). Additionally, these programs made use of costly flight demonstrations and qualification/certification programs ( $\$ 100$ s millions); e.g., unmanned Apollo capsules, F-104 Shuttle materials aerodynamic testing, and Shuttle TPS/Reinforced Carbon-Carbon (RCC) certifications.

Since the time of the Apollo, Shuttle, and Viking programs, new and improved lightweight ablatives, nonablative ceramics, inflatable structures, and ceramic matrix composites (CMCs) have been developed which show promise for use as heat shield materials (Williams, S.D., Gietzel, M.M., Rochelle, W.C., and Curry, D.M., 1991; Rasky, D.J., 1997). 
Based upon the assumption that maximizing thermal performance minimizes vehicle weight, most (if not all) testing and characterization of new TPS materials has concentrated on thermal response measurements and thermal predictions to mature the materials. While these materials vary in their level of maturity, most have undergone virtually no relevant environments testing and, with the exception of thermal performance, only limited material property testing. Thus TPS materials testing, to date, has provided data and the justification for development, but not the qualification (or insertion into a program or mission) of a new TPS material.

Thermal testing has matured some TPS materials to NASA Technology Readiness Level (TRL) 5 with respect to thermal performance. These materials, along with other lower TRL materials, remain at lower TRLs (2 to 4) for non-thermal material properties, space environmental effects, mission/life performance, and reliability. The major issues with the Space Shuttle tiles were not related to thermal performance, but rather strength, debris/impact resistance, and water absorption. These non-thermal property and environmental effects have created a significant operations and cost burden for the Shuttle Program, thus highlighting the importance of carefully characterizing the capabilities of TPS materials prior to incorporating them into vehicle development efforts. The progression from low to high TRLs generally involves significant increases in the complexity of the tests and in the funding required (Fig. 1).

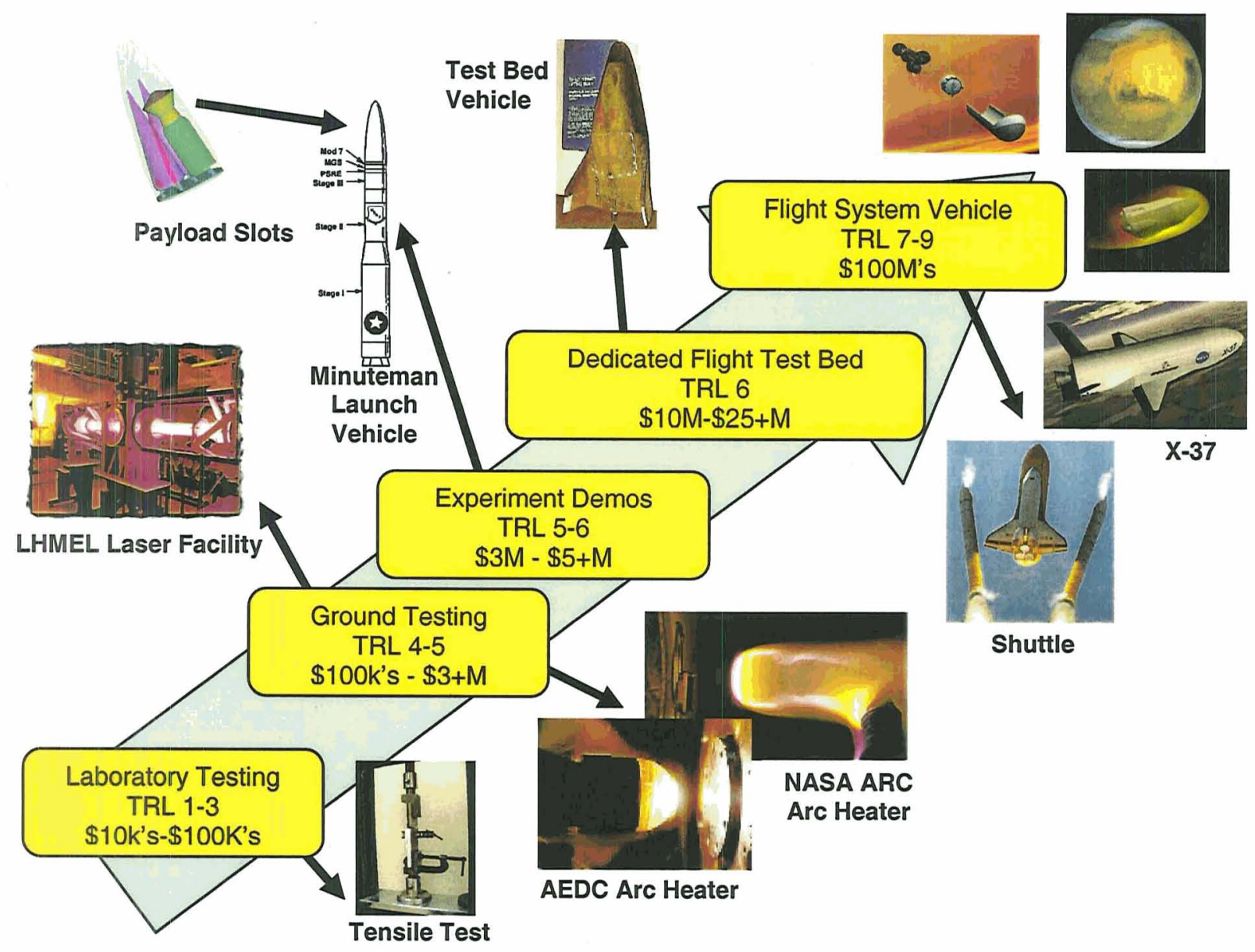

FIGURE 1. TPS Material Thermal Performance Development Process.

New preliminary architectures being developed by the NASA Explorations Systems Mission Directorate, which make use of aerocapture, aerobraking, and/or direct aeroentry to/from the Earth and Mars for both robotic and human missions, induce a different set of environments for TPS materials than those experienced by Apollo capsules (direct aeroentry, upon returning from the Moon) and Shuttle Orbiters (aeroentry from low-Earth orbit). Under the new Exploration Systems missions and architectures, the tried and true materials may no longer suffice for small 
payloads and will not work for larger payloads and human-rated vehicles. While present day analysis capabilities have reduced the need for expensive flight demonstrations, they have increased the need for high fidelity material property databases in order to make accurate material performance predictions. Furthermore, because a system of systems vehicle development approach is being pursued, and because a variety of missions and architectures are currently being considered, new TPS material development, qualification, and certification requires the development of an approach that takes into account not just material property testing, space environmental effects testing (1989), and simulated aerodynamic maneuver (arc jet) testing, but also design reference missions, vehicle-derived requirements, relevant environmental conditions, material technology plans and roadmaps, and material selection approaches.

\section{PROJECT OBJECTIVES}

Over the next several years, as the missions and architectures are defined for both human-rated and robotic vehicles for Exploration Systems Mission Directorate programs, the TPS materials and associated technologies available will play a major role in helping to define the vehicles to be developed for going both to the Moon and to Mars. Therefore, the primary objective of this technology project is to establish the TPS material technology roadmap, development methodology and plan, and screening testing process to mature lightweight non-metallic TPS materials. Additionally, screening tests will enable the development of a TPS database to enable the comparison and assessment of candidate TPS materials by Exploration Systems vehicle designers. The screening tests will result in not only the measurement of key TPS material properties, but also assessments of the materials performance characteristics in relevant planetary gases (both simulated Earth and Mars atmospheres) and in pertinent space environmental conditions. To further aid vehicle designers, the identification of TPS materials that can provide weight savings in the range of $5-20 \%$ is also an objective of this technology effort.

Generation of TPS material roadmaps and development plans, and conducting screening tests to determine relevant material properties and performance capabilities in relevant environments, will allow the early identification of areas that require more focused development efforts by the Exploration Systems team. Thus, the groundwork will be established for the eventual qualification and certification of the TPS and heat shield materials to be used on Constellation Systems vehicles. It is important to note that this project is not concentrating on a single material or design solution. It is applicable to multiple missions and vehicle design concepts, and will provide valuable tools for the eventual selection of specific TPS materials when the mission-specific transportation systems and spacecraft are developed.

\section{APPROACH AND METHODOLOGY}

The approach being taken for this TPS technology project will be to first establish a baseline of (a) requirements and environments and (b) material technology plans. From these, test matrices will be developed to characterize and assess candidate TPS materials and structures. Making use of these test matrices, screening tests will be performed to measure both material properties and material behavior in relevant space and aerodynamic maneuver environments. Testing performed will not generate statistically significant material properties or performance data for any one given material (such material allowables will be generated by testing in follow-on programs in order to get to TRL 6). Testing will provide data needed for qualitative comparison of the materials and of the performance of the four material classes of interest: lightweight ablatives, nonablative ceramics, inflatable structures, and CMCs (Table 1). Furthermore, testing will help define key properties and parameters that (a) drive TPS material development, (b) are needed to support Exploration Systems mission/architecture and design trade studies, and (c) are necessary to define cost effective material characterization and qualification processes and plans. Three cycles or spirals of requirements/environments definition, technology plan development, and material testing will be conducted (Fig. 2). Cycles II and III will document improvements over the previous cycle, thus reducing future costs to test and evaluate materials. At approximately the end of each cycle, a Government/Industry TPS Materials Summit will be held to present test results, to evaluate progress, to facilitate industry involvement in the project, and to recommend changes to the approach and plans being pursued. Close coordination with other Exploration Systems Mission Directorate projects and studies will thus facilitate efficient and timely input into other projects, specifically, the Exploration Systems vehicle design and development efforts. 
TABLE 1. Preliminary Candidate List of TPS Materials.

\begin{tabular}{|c|c|c|}
\hline Material Type or Class & \multicolumn{2}{|c|}{ Candidate Materials } \\
\hline Lightweight ablatives & $\begin{array}{l}\text { LMA SLA } \\
\text { ARA SRAM }\end{array}$ & $\begin{array}{l}\text { ARC SIRCA } \\
\text { ARC PICA }\end{array}$ \\
\hline Nonablative ceramics & $\begin{array}{l}\text { ARC ceramic foams } \\
\text { ARC TUFI-HT } \\
\text { ARC TUFROC }\end{array}$ & $\begin{array}{l}\text { Aspen Aerogel } \\
\text { ARC Aerogel }\end{array}$ \\
\hline Inflatable Structures & $\begin{array}{l}\text { BA Ballute/Inflatable } \\
\text { LMA Ballute/Inflatable }\end{array}$ & \\
\hline $\mathrm{CMCs}$ & $\begin{array}{l}\text { 2D/3D C-C } \\
\text { 2D/3D C-SiC }\end{array}$ & 2D CMC-overwrapped tiles \\
\hline $\begin{array}{l}\text { Baseline/Reference Standard } \\
\text { Materials }\end{array}$ & $\begin{array}{l}\text { Viking SLA-561 TPS ablator } \\
\text { Shuttle Orbiter RCG Tile }\end{array}$ & Shuttle Orbiter RCC \\
\hline $\begin{array}{l}\text { Acronyms: } \\
\text { ARA = Applied Research As } \\
\text { Ceramic Matrix Composite; } \\
\text { Impregnated Carbon Ablative; } \\
\text { Reusable Ceramic Ablative; } \\
\text { Thermal Protection System; } 1 \\
\text { Uni-piece Fibrous Refractory }\end{array}$ & $\begin{array}{l}\text { es Research Center; BA = Ba } \\
\text { ilicon-Carbon; LMA = Lock } \\
\text { arbon-Carbon; RCG = Reactio } \\
\text { weight Ablative; SRAM = Si } \\
\text { d Uni-piece Fibrous Insulation } \\
\text { ramic; } 2 \mathrm{D}=\text { Two Directional; }\end{array}$ & $\begin{array}{l}\text { ace; } \mathrm{C}-\mathrm{C}=\text { Carbon-Carbon; } \mathrm{CMC}= \\
\text { artin Aerospace; PICA = Phenolic } \\
\text { Glass; SIRCA = Silicone Impregnated } \\
\text { einforced Ablative Material; TPS = } \\
\text { Temperature; TUFROC = Toughened } \\
\text { ree Directional. }\end{array}$ \\
\hline
\end{tabular}

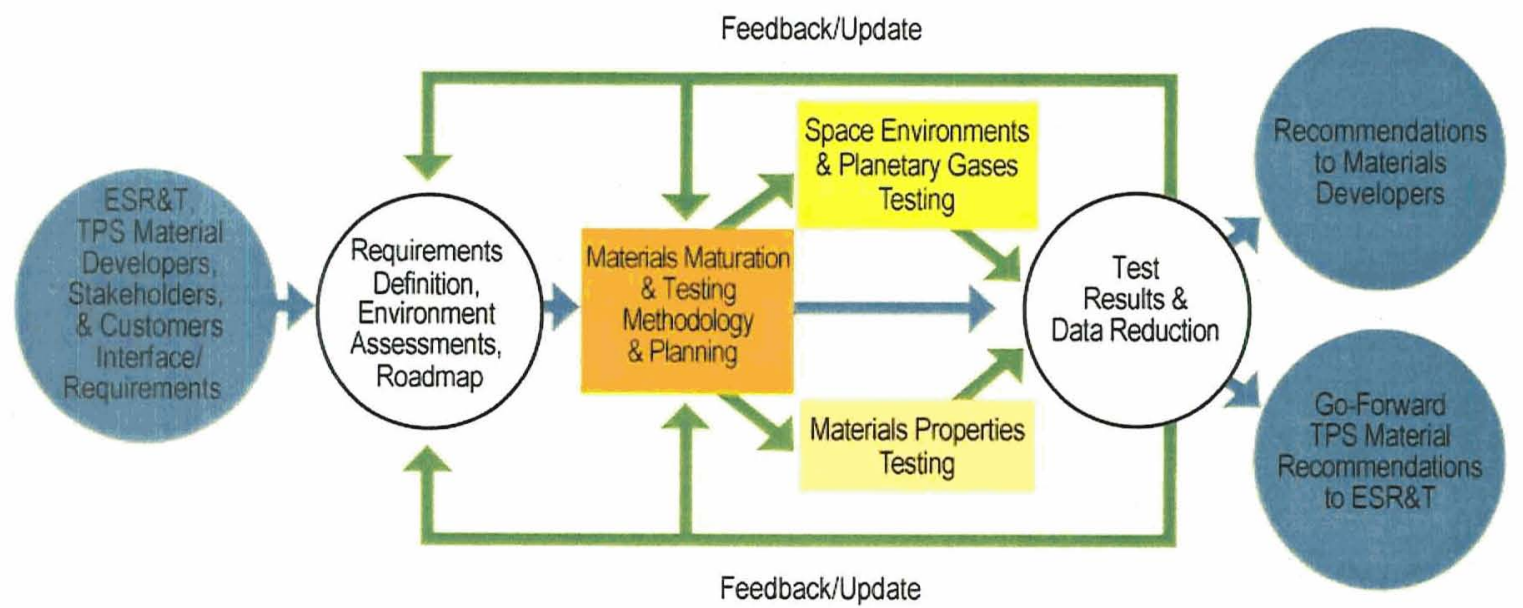

FIGURE 2. Requirements and Process Flow.

For the requirements and environments definition portion of the project, the reference missions to be considered will be include (a) aeroentry, aerocapture, and aerobraking for both Earth and Mars, (b) long-duration deep-space exposures, including transit between Earth and Mars and long-duration Lunar orbit, and (c) long-duration low-Earth and low-Mars orbits. Evaluation of the reference missions will include the determination of relevant space environments, the planetary environments associated with the pertinent aerodynamic braking maneuvers, and the corresponding TPS material requirements. From these evaluations, the definition of relevant test conditions, the development of a recommended TPS material technology roadmap, and the development of a recommended process plan for qualification and human-rating of TPS materials will be derived. Development plans will be generated for each of the four classes of TPS materials being considered under this project (Table 1). Additionally, for each material class, the relevant material properties for which data is required and the specific space environmental requirements that must be assessed will be determined. Finally, test plans and matrices will be generated for the candidate materials. 
Material property and environmental testing and procedures will be based initially on the standards developed for the Space Shuttle, the International Space Station (ISS), and various planetary mission spacecraft. Testing will involve typical parametric screening testing of the materials, using only a few samples of each candidate material. By evaluating multiple materials of the same class, relevant performance information for a specific material type or class will be obtained. Testing will also evaluate which material properties/parameters must be considered in order to space-rate materials. Screening testing will be performed to provide a means to gain knowledge of key TPS material properties, characteristics, and performance capabilities in relevant planetary gas environments and under space environmental conditions. The screening studies will involve the measurement of material properties and the performance of the TPS materials in simulated space and aerodynamic braking maneuver environments (see Tables 2 and 3).

TABLE 2. Initial List of TPS Material Property Tests.

\begin{tabular}{l|l}
\hline Property & Test \\
\hline Physical & density, microstructure, materials compatibility \\
\hline Thermal & conductivity, emissivity, specific heat, coefficient of thermal expansion (CTE) \\
\hline Mechanical & tension, compression, shear, acoustic/vibration \\
\hline Multiparameter & stressed oxidation \\
\hline *Note: Some testing will be performed
\end{tabular}

*Note: Some testing will be performed at cryogenic, room, and elevated temperatures.

TABLE 3. Initial List of TPS Material Space Environment Tests.

\begin{tabular}{l|l}
\hline Space Environments & $\begin{array}{l}\text { Atomic oxygen (AO); radiation [electron and proton fluxes, ultraviolet (UV)]; } \\
\text { micrometeroid/orbital debris (MMOD) (hypervelocity impact) }\end{array}$ \\
\hline $\begin{array}{l}\text { Aeroentry, Aerocapture, } \\
\text { Aerobraking Effects }\end{array}$ & Arc jet -Earth gases; arc jet-Mars gases
\end{tabular}

To ensure the greatest relevance to other on-going Exploration Systems efforts and to industry-led activities, a Request for Information (RFI) will be issued to obtain input from the aerospace primes and the TPS material manufacturers on what materials they believe should be included in the list of candidate materials to be tested in the first of the three screening studies. The first two screening studies performed will be followed by a materials downselection prior to a third cycle of more focused testing. In the first two screening studies, 16 to 24 candidate materials will be investigated using tests of the types presented above (Tables 2 and 3), enabling a down-selection to the more promising materials. After the second screening study, approximately seven materials will be selected for the third round of more focused testing: one or two from each of the four classes of materials under consideration (lightweight ablatives, nonablative ceramics, infiatable structures, and CMCs). Additionally, to more fully assess the merits of the TPS materials being investigated in this project, limited testing will be performed on the current NASA baseline materials (or standards), i.e., the Space Shuttle and Viking TPS materials.

In this project, no new TPS materials will be developed. However, it is recognized that existing previouslydeveloped TPS materials may be at different TRLs ( 2 through 5). As such, one purpose of the project will be to mature one or two materials in each material class to TRL 4 or 5 for the suite of material properties and space environments defined in the roadmap/plan, i.e., those properties and environments that have been determined to be key for qualification and human-rating. Additionally, the project will also define how promising materials can be further developed (in follow-on programs) to TRL 6 to meet the needs of the vehicles being developed under the Exploration Systems effort.

\section{SUMMARY}

As a collaborative effort among several of the NASA Centers, this new thermal protection materials technology effort aims to provide relevant and timely TPS information to the vehicle and spacecraft designers working on Exploration Systems Mission Directorate programs. By examining the environments associated both with the aerodynamic braking maneuvers associated with new missions to the Moon and Mars and with the space 
environmental effects of long-duration exposures, this project will result in the following: (a) the development of a TPS material technology roadmap early on in the new Exploration Systems effort; (b) the generation of an improved, streamlined building-block approach for developing, characterizing, and qualifying TPS materials for space rating and/or human rating which will also minimize life cycle costs and time to market; (c) the creation and characterization of improved methodology plans, flowcharts, and procedures for TPS material development for space exploration applications; (d) the identification of key parameters and properties of TPS materials for use in steering development and for maximizing return on development costs; (e) the screening of TPS materials in relevant environments, thus advancing the materials to TRL 4 or 5; (f) the facilitation of the transfer of information to industry; and (g) the formulation of recommendations and requirements for follow-on projects to further develop, test, and qualify/human-rate promising TPS materials. By performing three cycles of technology definition, development, and testing over four years, the resultant maturation of TPS materials and technology will support Exploration Systems spiral development approach to designing, building, and operating new exploration vehicles and spacecraft.

\section{ACKNOWLEDGMENTS}

Fig. 1 courtesy of Dr. Gerald Russell, U.S. Army, Redstone Arsenal, AL.

\section{REFERENCES}

Chauvin, L.T., Erb, R.B., Greenshields, D.H., Pavlosky, J.E., and Statham, C.L., "Apollo thermal-protection system development," in Entry Vehicle Systems and Technology Meeting, American Institute of Aeronautics and Astronautics, Williamsburg, VA, NASA Center for AeroSpace Information (CASI), AIAA PAPER 68-1142, 3-5 December 1968, $19700601 ; 1$ June 1970.

Greenshields, D.H., "Orbiter Thermal Protection System Development," NASA Center for AeroSpace Information (CASI), Space Congress, Cocoa Beach, FL, 27-29 April 1977, 19770101,1 January 1977.

Pavlosky, J.E. and St.leger, L.G., “Apollo Experience Report: Thermal Protection Subsystem," NASA Center for AeroSpace Information (CASI), NASA-TN-D-7564, JSC-S-383, 19740101, 1 January 1974.

Rasky, D.J., "TPS Materials for Planetary Exploration," NASA Ames Research Center, Moffett Field, CA, United States, NASA Center for AeroSpace Information (CASI), 1997.

Schaefer, J.W., Flood, D.T., Reese, J.J., Jr., and Clark, K.J., "Experimental and Analytical Evaluation of the Apollo Thermal Protection System under Simulated Reentry Conditions, Part 1: Program Description and Presentation of Results," NASA Center for AeroSpace Information (CASI), NASA-CR-65817, REPT-67-16-PT-1, NAS 1.26:65817, 19670715, 15 July 1967.

Schaefer, J.W., Flood, D.T., Reese, J.J., Jr., and Kimble, J.C., "Experimental and Analytical Evaluation of the Apollo Thermal Protection System under Simulated Reentry Conditions, Part 2: Analysis of Results," NASA Center for AeroSpace Information (CASI), NASA-CR-65818, REPT-67-16-PT-2, NAS 1.26:65818, 19670715, 15 July 1967.

Williams, S.D., Gietzel, M.M., Rochelle, W.C., and Curry, D.M., "TPS Design for Aerobraking at Earth and Mars," NASA Center for AeroSpace Information (CASI), NASA-TM-104739, S-645, NAS 1.15:104739, 19910801, 1 August 1991.

"Shuttle Orbiter Thermal Protection System Test Plan, Volume I, Materials Characterization Test Program," SD74-SH-0156-1, 13 May 1974.

"Shuttle Orbiter Thermal Protection System Test Plan, Volume II, Design Development Test Program," SD74-SH-156-2, 13 May 1974.

"Shuttle Orbiter Thermal Protection Subsystem Certification Plan," SD74-SH-0282D, 30 June 1980.

"NASA/SDIO Space Environmental Effects on Materials Workshop" proceedings, NASA Conference Publication 3035, Parts 1 and 2, May 1989.

"The Vision for Space Exploration," National Aeronautics and Space Administration, NASA Headquarters Website

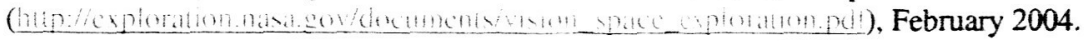

